Manohisoa RAKotondRABE ${ }^{1}$

Sigrid AUBERT ${ }^{1,2}$

Jules RAZAFIARIJAONA ${ }^{1}$

Sylvain RAMANANARIVO ${ }^{1}$

Romaine RAMANANARIVO ${ }^{1}$

Martine ANTONA ${ }^{2}$

1 Université d'Antananarivo

École supérieure des sciences

agronomiques

Agro-Management

Antananarivo

Madagascar

${ }^{2}$ Cirad

\title{
Les paiements pour services environnementaux : un moyen de contenir les cultures sur brûlis forestier à Madagascar ?
}

UPR 47 Green

Campus international de Baillarguet

34398 Montpellier Cedex 5

France

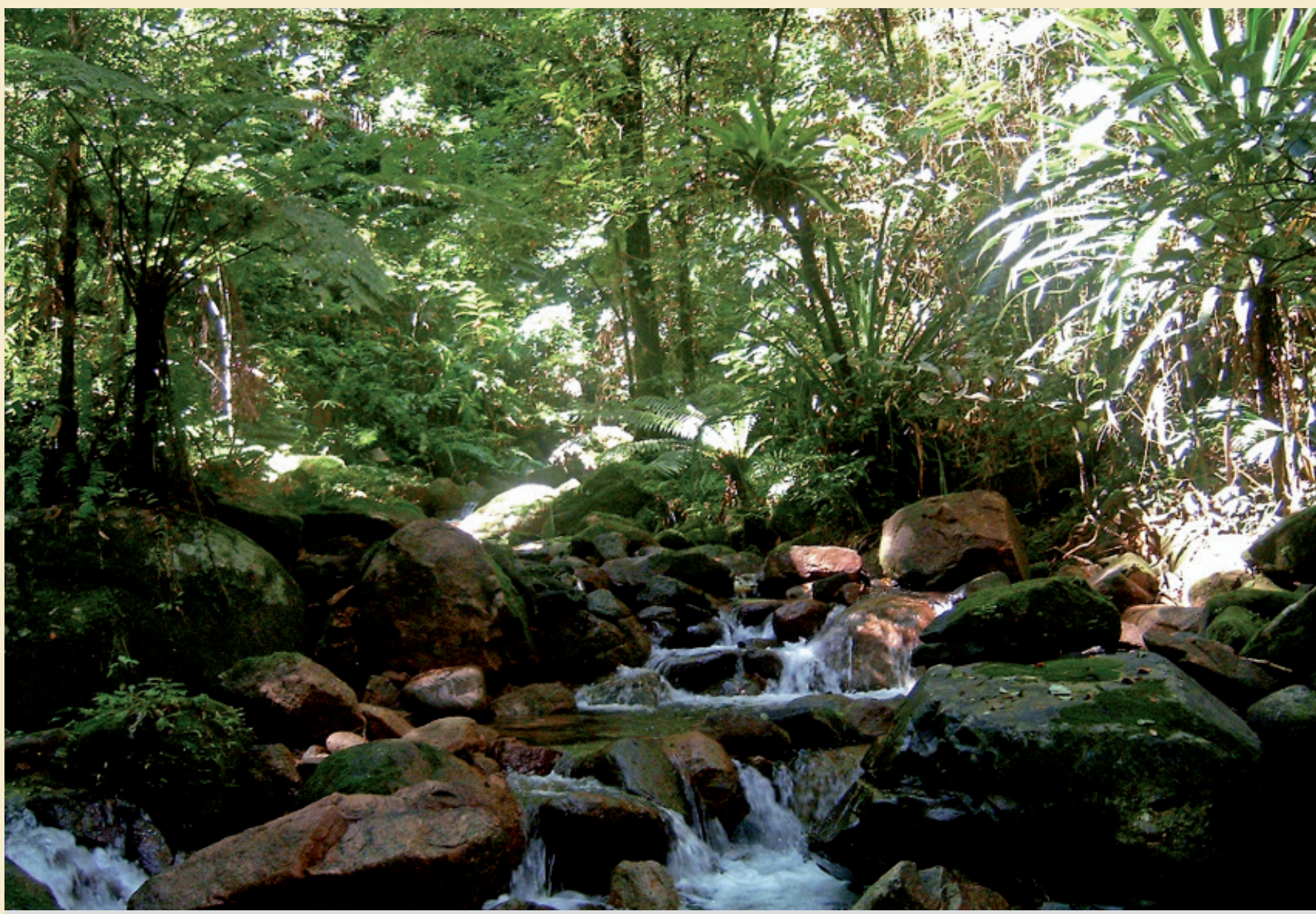

Photo 1.

Cours d'eau en amont du bassin versant de Sahamazava, Andapa.

Photo M. Rakotondrabe. 


\section{RÉSUMÉ}

\section{LES PAIEMENTS POUR SERVICES \\ ENVIRONNEMENTAUX : UN MOYEN DE CONTENIR LES CULTURES SUR BRÔLIS FORESTIER À MADAGASCAR ?}

La déforestation massive dans la partie Nord-Est de Madagascar, notamment à Andapa, grenier à riz de la région SAVA (région regroupant quatre districts dans la partie Nord-Est de Madagascar qui sont : Sambava, Andapa, Vohémar et Antalaha), entraîne l'érosion des bassins versants et l'ensablement de la plaine rizicole. En amont du bassin versant de Sahamazava, la culture sur brûlis forestier participe à une stratégie de survie des ménages agricoles les plus démunis. Ces pratiques perturbent également l'approvisionnement en eau potable de la commune urbaine d'Andapa. Un système de Paiements pour Services Environnementaux (PSE) a été envisagé en vue de réorienter le comportement des agriculteurs défricheurs. Le mécanisme promeut l'abandon de l'agriculture itinérante sur brûlis forestier (tavy) au profit de la pratique de cultures pérennes en amont du bassin versant. Des questions se posent quant aux conditions de mise en place et de pérennisation de ce dispositif. La présente étude se propose de mettre en exergue l'importance de l'appréciation des besoins locaux dans le contexte de la mise en place d'un PSE dans un pays en développement. À partir de trois scénarios différents, elle retrace l'évolution des exploitations agricoles avant et après l'établissement de l'interdiction de défricher la forêt sur le bassin versant de Sahamazava, alors que les compensations liées à la réduction des droits d'accès ne sont pas encore effectives. Des pistes d'actions précisant l'affectation des compensations attendues sont finalement proposées.

Mots-clés : paiement pour services environnementaux, investissements, sécurisation foncière, gestion durable des ressources naturelles, Madagascar.

\section{ABSTRACT}

\section{PAYMENT FOR ENVIRONMENTAL SERVICES AS A MEANS OF CONTROLLING SLASH-AND-BURN CULTIVATION IN MADAGASCAR'S FORESTS}

Large-scale deforestation in north-eastern Madagascar, especially around Andapa, which is the main rice-growing area in the SAVA region comprising the districts of Sambava, Andapa, Vohémar and Antalaha, is causing erosion in catchment basins and silting up the floodplain where the rice is grown. Upstream from the Sahamazava catchment basin, slash-andburn cultivation is a means of survival for the most impoverished farming households, but it is disrupting drinking water supplies to the Andapa Urban Community. A system of Payments for Environmental Services (PES) has been considered to encourage a change of practice among slash-and-burn farmers. The scheme encourages them to abandon slash-andburn cultivation (tavy) in favour of perennial crops upstream from the catchment basin, but questions have arisen over its conditions of implementation and sustainability. This study emphasises the importance of assessing local needs when a PES is to be implemented in a developing country. Using three different scenarios, it follows farming developments before and after the ban on slashing and burning was introduced in the forests of the Sahamazava catchment basin, at a time when compensation for access restrictions was not yet in place. Potential remedies specifying the allocation of expected compensations are finally proposed.

Keywords: payment for environmental services, investments, land tenure security, sustainable natural resource, Madagascar.

\section{RESUMEN}

\section{PAGOS POR SERVICIOS AMBIENTALES: ¿UN MEDIO PARA CONTENER LOS CULTIVOS CON QUEMA DE MONTE EN MADAGASCAR?}

La deforestación masiva en la parte noreste de Madagascar, especialmente en Andapa, granero de arroz de la región SAVA, región que reúne cuatro distritos: Sambava, Andapa, Vohémar y Antalaha, provoca la erosión de las cuencas de drenaje y el enarenamiento de la llanura arrocera. En la cabecera de la cuenca de drenaje de Sahamazava, el cultivo con quema de monte forma parte de una estrategia de supervivencia de los hogares agrícolas más pobres. Estas prácticas también alteran el abastecimiento de agua potable de la Comunidad Urbana de Andapa. Se pensó en un sistema de Pagos por Servicios Ambientales (PSA) para reorientar el comportamiento de los agricultores de roza y quema. El mecanismo promete el abandono de la agricultura itinerante con quema de monte (tavy) para establecer cultivos permanentes en la cabecera de la cuenca de drenaje. Existen interrogantes relativos a las condiciones para establecer y perpetuar este dispositivo. El presente estudio se propone resaltar la importancia de la apreciación de las necesidades locales en el marco del establecimiento de un PSA en un país en desarrollo. A partir de tres escenarios diferentes, el estudio reconstituye la evolución de las explotaciones agrícolas antes y después de la prohibición de desbrozar el bosque en la cuenca de drenaje de Sahamazava, cuando las compensaciones por la reducción de los derechos de acceso aún no se han efectuado. Finalmente se proponen líneas de acción especificando la asignación de la indemnización prevista.

Palabras clave: pagos por servicios ambientales, inversiones, seguridad en tenencia de tierras, manejo sostenible de los recursos naturales, Madagascar. 


\section{Introduction}

À partir de la seconde moitié des années 2000, et notamment dans le cadre du Programme environnemental 3 (PE3) (2005-2009), les paiements pour services environnementaux (PSE) apparaissent comme un moyen de contribuer au financement durable des actions environnementales initiées à Madagascar (Andriamahefazafy et al., 2007). L'engagement international visant la réduction des émissions de gaz à effet de serre dues à la déforestation et à la dégradation des forêts et l'investissement du gouvernement malgache dans la préparation d'une stratégie nationale en la matière (Carret et al., 2009 ; MEF, 2014) ont servi de base à l'établissement des premiers PSE. Cet outil est mobilisé pour promouvoir les changements de comportement attendus des populations locales en vue de l'établissement d'une gestion durable de la biodiversité, mais également de l'eau (Andriamahefazafy, 2011).

Dans la région SAVA ${ }^{1}$, le district d'Andapa présente une forte potentialité agricole et une importante biodiversité. II comprend une cuvette de sédimentation propice à la riziculture de bas-fond qui fait sa réputation de premier grenier à riz de la région. Cette cuvette est entourée d'espaces inclus dans le Système des aires protégées de Madagascar (SAPM) comprenant le Parc national de Marojejy, la Réserve spéciale d'Anjanaharibe-Sud et plusieurs forêts classées (figure 1).

Les forêts du bassin versant font cependant l'objet d'intenses défrichements par les agriculteurs à la recherche de terres fertiles suite à la saturation des bas-fonds (BVPI, 2006) et à la diminution des revenus tirés des cultures de rente, dont notamment la vanille (MAEP, 2006). Ces défrichements ont été identifiés comme étant la principale cause de la diminution de la qualité et de la quantité de l'eau utilisée, en aval, par les agriculteurs des périmètres irrigués et par les habitants de la ville d'Andapa (Andriamahefazafy, 2011 ; CahenFourot, 2011) (photo 1). La relation entre la déforestation et l'état du système hydrique doit cependant encore être précisée à l'échelle locale (Bruijnzeel et al., 2008 ; Karsenty et al., 2009 ; Toillier, 2011).

La mise en place d'un PSE «Eau » a été engagée à la fin de l'année 2009 à Andapa par l'Association des paysans de montagne du monde (APMM) en collaboration avec le World Wild Fund (WWF). Ce mécanisme vise à réduire les défrichements dans un périmètre de 42 ha situé en amont du bassin versant de Sahamazava, où sont localisées les principales sources alimentant les cours d'eau qui, en aval, sont utilisés par le réseau d'adduction d'eau potable de la commune urbaine d'Andapa. Les 32 ménages agricoles qui cultivaient dans ce périmètre ont été identifiés comme des « fournis- seurs de services environnementaux » potentiels. Un contrat de PSE préconisant l'abandon des cultures annuelles sur brûlis forestier (tavy) et prévoyant le versement de compensations financières permettant leur remplacement par des vergers et des plantations de raphia ou d'acacias ${ }^{2}$ leur a été proposé. Ce contrat a été signé pour une durée de quatre années renouvelables et a posé le principe de versement d'une compensation directe d'environ 70000 euros aux ménages fournisseurs de services environnementaux, cette somme devant être répartie en fonction des superficies de cultures annuelles abandonnées.

Lors de son lancement, le mécanisme de PSE a été favorablement accueilli par les populations rurales. Grâce aux activités du projet ${ }^{3}$, les restrictions d'usage ont été respectées et les populations se sont investies dans le changement de leurs pratiques agricoles. Par contre, le versement des compensations financières envisagé dans le cadre du PSE a été différé face aux difficultés liées à la mise en place d'un système de redistribution pérenne alimenté par les usagers de l'eau de la ville d'Andapa, identifiés comme les " acheteurs de services environnementaux ».

${ }^{1}$ La région SAVA est une région regroupant quatre districts dans la partie nord-est de Madagascar qui sont : Sambava, Andapa, Vohémar et Antalaha.

2 Donc de cultures pérennes à faible rotation.

${ }^{3}$ Le projet appuyant la mise en place du mécanisme de PSE-Eau prévoyait d'accompagner l'évolution du système agraire par le remboursement/dédommagement des dépenses déjà engagées dans les cultures annuelles, la fourniture de semences et d'engrais, l'achat de matériels et d'équipements agricoles, la tenue de séances de formation, et la mise en place d'un système de coopérative pour la commercialisation des produits issus des cultures pérennes. D'autres activités de substitution (apiculture, vannerie...) ont également été développées et l'ONG Care International a fourni de jeunes plants d'acacia et de raphia aux agriculteurs.

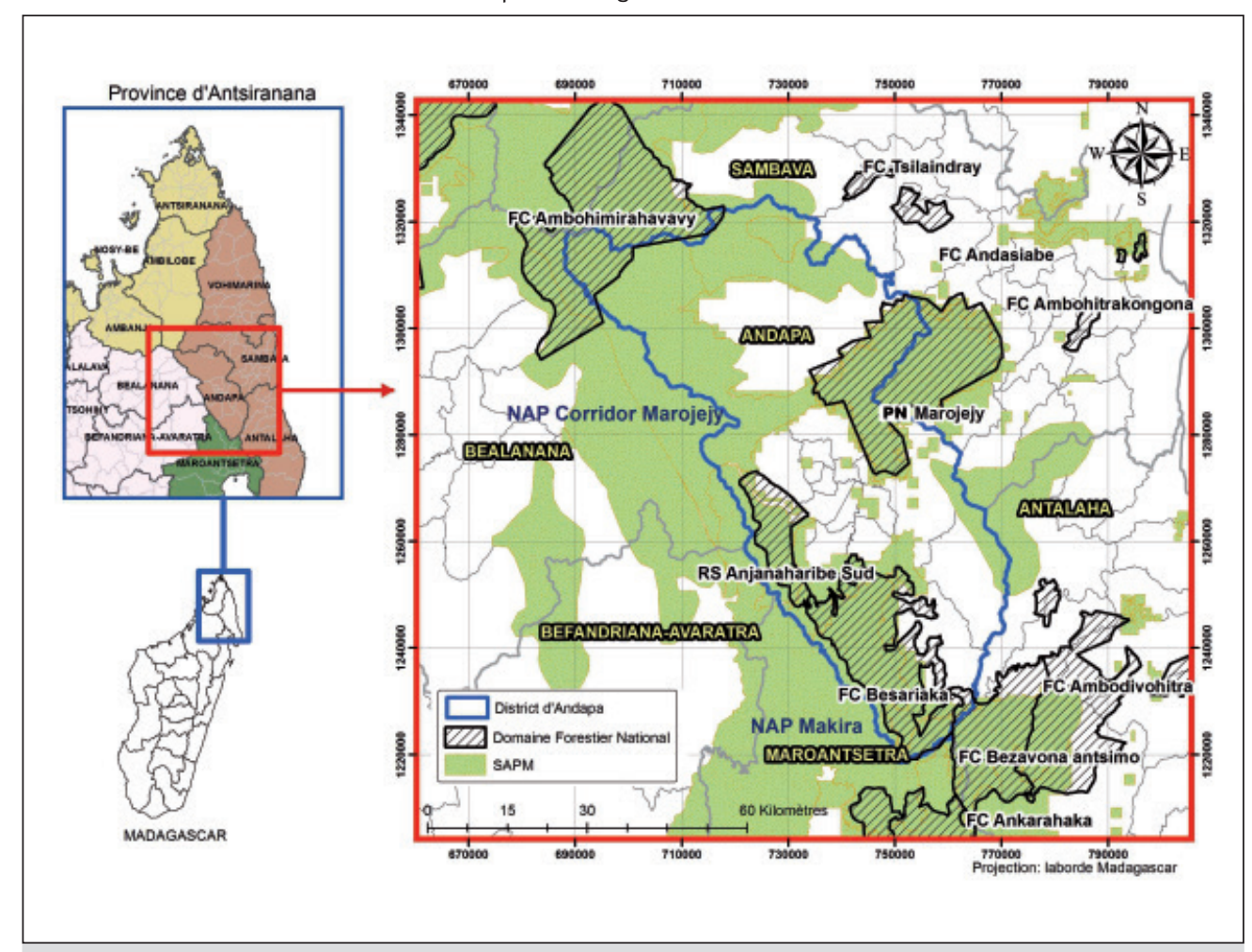

Figure 1.

Localisation du district d'Andapa, Madagascar. 


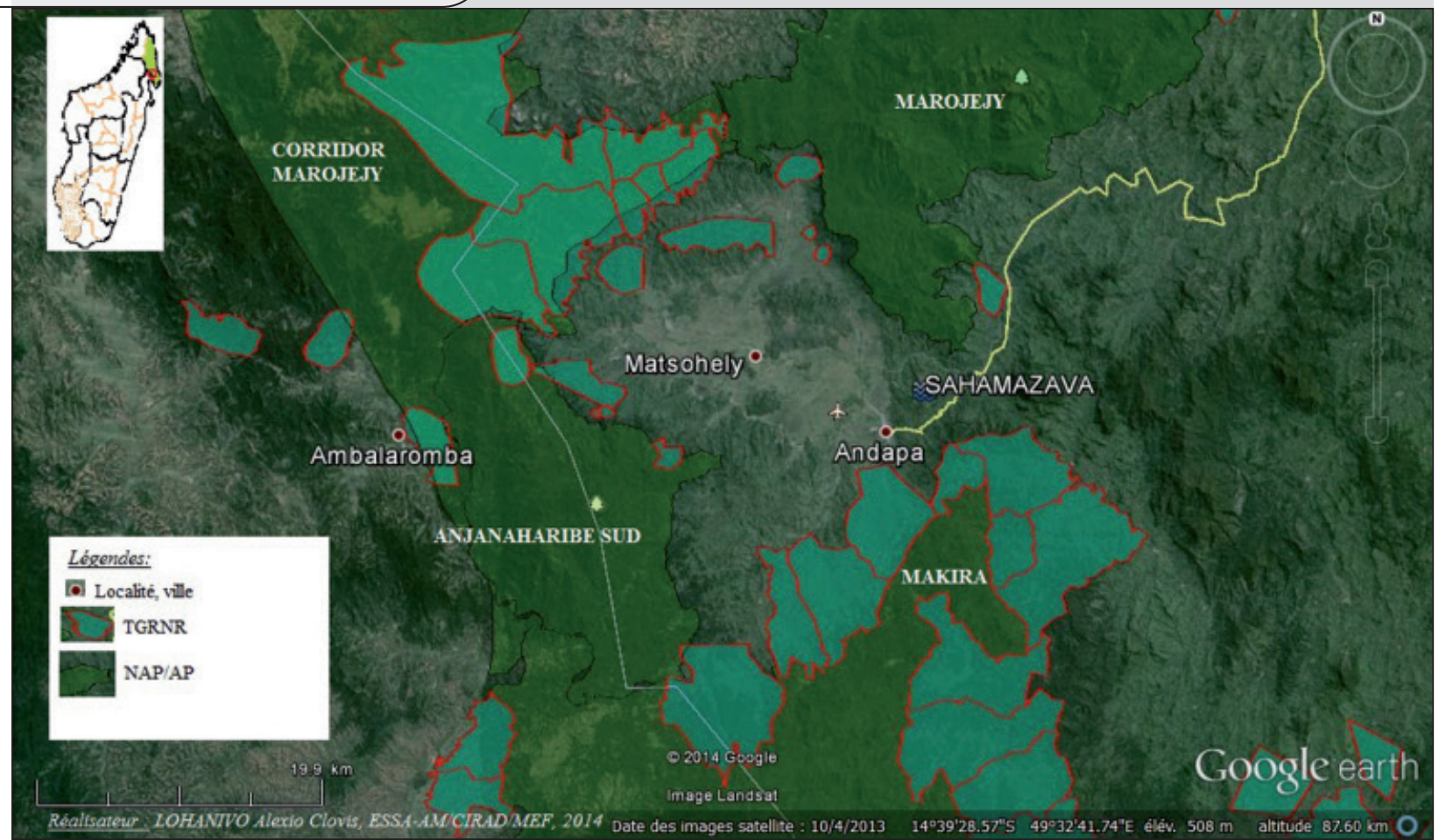

Figure 2.

Localisation du périmètre cible de restriction des droits d'usage des fournisseurs de services environnementaux par rapport aux usagers de l'eau de la commune d'Andapa, et des transferts de gestion des ressources naturelles renouvelables (TGRNR).

Dans ces conditions, bien que les revenus des exploitants agricoles aient augmenté, leur vulnérabilité s'est accrue : leur autoconsommation a diminué et ils dépendent désormais des marchés pour assurer leur survie. Aujourd'hui, la durabilité des changements de pratiques agricoles est remise en question.

À partir d'un travail d'enquête et de modélisation, cette étude propose d'apprécier l'impact de l'abandon des cultures sur brûlis forestier dans le périmètre cible sur les systèmes de production et les revenus de la population d'agriculteurs fournisseurs de services environnementaux. Une analyse des besoins en superficies agricoles nécessaires pour compenser l'abandon de la culture sur tavy permet ensuite d'apprécier l'importance des investissements susceptibles d'être effectués, dans l'hypothèse où les compensations attendues seraient effectivement versées.

Cette étude permet de mettre en exergue certains éléments qui entravent la mise en place des PSE dans les pays en développement et propose des pistes permettant de mieux appréhender ce mécanisme dans l'objectif de réduire la culture sur brûlis forestier, considérée comme la principale cause de la déforestation à Madagascar (Aubert et Razafiarison, 2003).

\footnotetext{
${ }_{4}^{4}$ L’Association Mamirano, créée à la fin de l'année 2009, regroupe les 32 ménages agricoles principaux usagers des terres en amont du bassin versant.

530600 habitants ont été recensés dans la CU d’Andapa en 2010.

${ }^{6}$ Les bornes-fontaines sont disposées sur la voie publique et permettent à $83 \%$ des foyers de la CU d'Andapa qui ne disposent pas de l'eau courante d'avoir de l'eau potable (http://fr.wikitionary.org/wiki/borne-fontaine 28/08/2012).

$717 \%$ des foyers de la CU d'Andapa.

$860 \%$ de ces prélèvements sont dits « taxes de consommation ». Elles reviennent à la Jirama en compensation des quantités d'eau " perdues" affectées à l'usage des bornes-fontaines. Les $40 \%$ restant sont dits " surtaxes sur fonds de travaux », et reviennent à la commune urbaine, qui agit en tant que maître d'ouvrage pour réaliser des améliorations d'infrastructures et étendre le réseau des bornes-fontaines.
}

\section{Caractérisation de la zone d’étude et démarche adoptée}

\section{Fonctionnement du mécanisme de PSE}

Situé à $5 \mathrm{~km}$ de la commune urbaine (CU) d'Andapa, le bassin versant de Sahamazava s'étend sur une superficie de 910 ha et abrite 2180 habitants. Les 42 ha inclus dans le périmètre cible de restriction des droits d'usage des fournisseurs de services environnementaux sont situés sur les sommets du bassin versant de Sahamazava (figure 2); ils constituent un espace de production agricole pour les 32 ménages qui y pratiquent le tavy.

Selon le mécanisme de PSE envisagé, l'abandon des cultures annuelles au profit de cultures pérennes permettrait aux 32 ménages bénéficiaires constitués en association $^{4}$ de percevoir une compensation financière issue du paiement d'une taxe mensuelle de 1000 MGA (ariary, monnaie malgache), soit l'équivalent de $0,30 €$ ou 0,41 US $\$$ par mois, payée par les usagers ${ }^{5}$ des bornes-fontaines ${ }^{6}$ de la CU d'Andapa. Une autre taxe, de $10 \%$ des factures mensuelles des abonnés ${ }^{7}$ de la compagnie en charge du réseau de distribution de l'eau potable (la Jirama), serait affectée à la réalisation des travaux nécessaires à l'extension du réseau des bornes-fontaines et à son entretien ${ }^{8}$. Une Plateforme de concertation ${ }^{9}$ a été chargée de suivre et de formaliser les négociations permettant la mise en place de ce mécanisme (figure 3).

9 La Plateforme de concertation (Tohampontsy) a pour rôle de formaliser et de contrôler les engagements des acteurs afin que les compensations soient effectivement versées aux fournisseurs de services environnementaux. 




Figure 3.

Schéma du fonctionnement du mécanisme PSE-Eau Andapa.

\section{Approches méthodologiques}

La collecte d'informations sur le terrain a été réalisée au moyen de focus groups ${ }^{10}$ et d'enquêtes individuelles conduites auprès de la totalité des 32 ménages agricoles concernés par le dispositif. Trois approches méthodologiques ont été adoptées.

\section{Approche socio-foncière}

L'approche socio-foncière a consisté à réaliser une typologie des 32 ménages agricoles identifiés comme fournisseurs potentiels de services environnementaux avant la restriction d'usage imposée par la mise en place du mécanisme de PSE, puis à refaire l'exercice une année après son établissement. Ces typologies sont obtenues en trois étapes : une classification ascendante hiérarchique $(\mathrm{CAH})$, permettant de faire un premier classement des ménages, une confirmation des classes obtenues par la classification de K-Means, et une analyse factorielle discriminante (AFD) permettant de caractériser les ménages.

Les variables utilisées sont les superficies affectées à chacun des espaces de production (EP) identifiés de la manière suivante :

- les bas-fonds, essentiellement composés de rizières (BF) ; - les versants sur lesquels s'établissent les habitations et diverses cultures pluviales ${ }^{11}(\mathrm{~V})$;

- les sommets protégés où s'établissent les forêts et les sources d'eau menacées par le tavy (ZP) ;

- les sommets non protégés qui n'abritent pas de sources et qui ne sont pas appréhendés dans le cadre du projet (ZNP).
Pour la zone de protection (ZP), les superficies affectées au tavy (CA) et celles attribuées aux cultures pérennes (CP) ont été distinguées (figure 4).

Ainsi, pour un ménage agricole donné, la superficie des terres mises en culture (STC) est donnée par l'équation suivante : $\mathrm{STC}=\mathrm{BF}+\mathrm{V}+\mathrm{ZNP}+\mathrm{CA}+\mathrm{CP}$.

Avec :

- STC, superficie des terres mises en culture ou espaces de production (EP) ;

- BF, bas-fonds ;

- ZNP, sommets non protégés ;

- CA, superficies affectées au tavy;

- CP, cultures pérennes.

Afin d'apprécier les tendances de l'évolution des superficies de terres mises en culture dans un futur proche, une analyse prospective par la chaîne de Markov a été effectuée. Il s'agit d'un croisement entre la matrice de la moyenne des surfaces utilisées par les agriculteurs et la matrice de corrélation des besoins en surface sur 10 ans : une première opération a été faite avec la situation qui prévalait avant l'interdiction du tavy, et une seconde opération, avec la situation où cette interdiction du tavy est effective.

Cette démarche permet de comprendre la stratégie de relocalisation des cultures en fonction des superficies cultivables par ménage dans chacune des deux situations appréhendées.

${ }^{10}$ Les discussions thématiques en groupe ont permis de faire émerger les problèmes des agriculteurs et rechercher collectivement des solutions pour y remédier.

11 Les cultures identifiées sur versant sont variées : haricots, maïs, manioc, café, vanille, etc. 


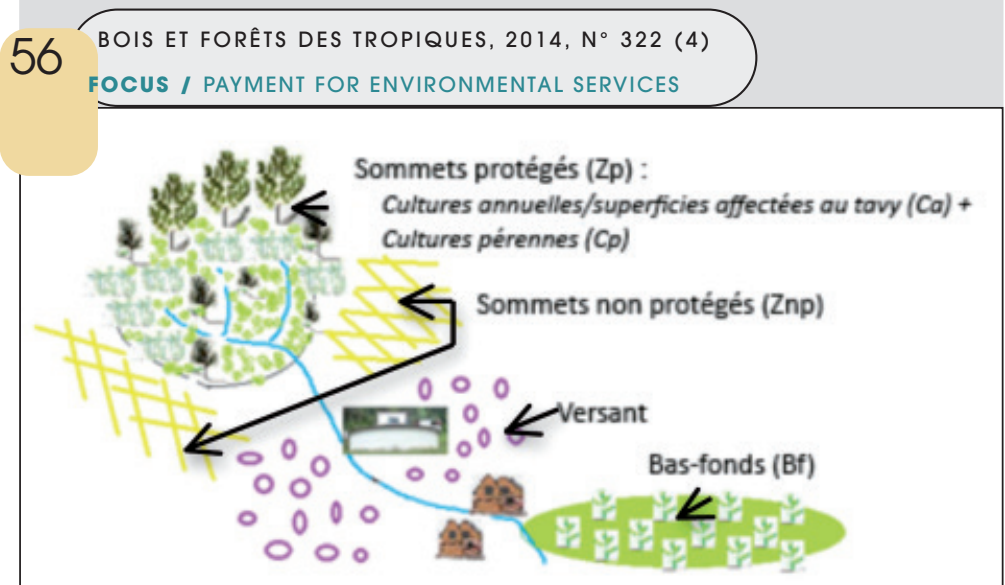

Figure 4.

Localisation des différents espaces de production dans la zone d'étude.

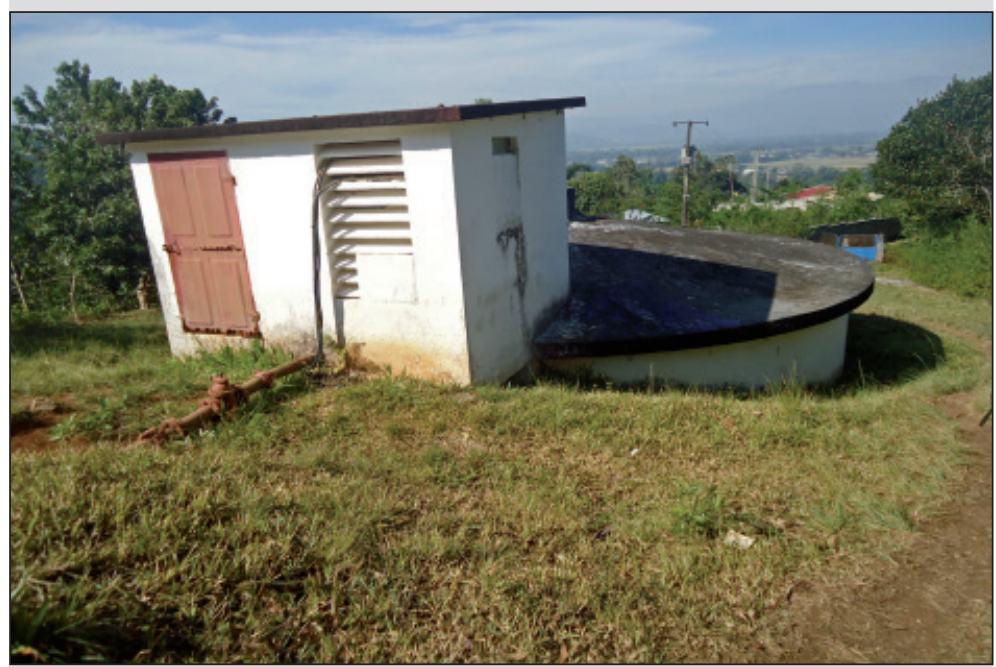

Photo 2.

Station de captage et d'épuration d'eau de la compagnie en charge du réseau de distribution de l'eau potable (JIRAMA) Photo M. Rakotondrabe.

\section{Approche comparative}

Une comparaison des états financiers de chacun des types de ménages agricoles précédemment identifiés a été effectuée. Les indicateurs choisis sont :

- le taux de rentabilité interne (TRI) et la trésorerie des ménages, retraçant les gains accumulés par les ménages sur chacun des espaces de production considérés ;

- le revenu agricole (RA), qui correspond à la somme perçue par ménage après recouvrement de l'ensemble des charges ${ }^{12}$.

Le calcul est fondé sur l'hypothèse de l'existence d'un marché stable permettant d'écouler l'ensemble des produits agricoles non affectés à l'autoconsommation. Le revenu agricole moyen calculé sur les 10 années des simulations a été ramené en \$US/jour/personne afin de pouvoir être comparé au seuil de survie de 1 \$US/jour/personne fixé par la Banque mondiale ${ }^{13}$.

Pour avoir une vision synthétique des états financiers, un calcul ramenant à une valeur moyenne actualisée des différents états financiers calculés sur les 10 années de simulation a été réalisé.

\footnotetext{
12 Les charges correspondent aux achats de semences et d'intrants agricoles, aux dépenses allouées aux salariés agricoles.
}

\section{Approche déductive basée sur les simulations précédemment réalisées sur 10 ans}

Cette approche permet d'apprécier l'importance des investissements requis dans chacun des espaces de production investis par les agriculteurs, compte tenu des stratégies déployées pour assurer leurs besoins de subsistance. À partir du constat réalisé en année 1 , elle se fonde sur deux calculs.

\section{Le calcul de la superficie devant être mise en culture pour compenser l'abandon du tavy}

Cette superficie est obtenue par le calcul du pourcentage d'augmentation de l'utilisation des terres d'une année à une autre (indice d'augmentation), puis de l'intégration de cet indice par rapport à la superficie de départ.

Il en résulte la superficie de terre à prévoir pour 10 ans par type de ménage et par espace de production. Les résultats sont ensuite restitués dans un tableau récapitulatif, dans lequel l'appréciation de la disponibilité des espaces de production à l'année 1 est notée comme suit :

+++ : espaces importants encore non cultivés, susceptibles d'accueillir les agriculteurs à la recherche de nouvelles terres ++ : pour les espaces encore non cultivés

+ : peu et/ou aucune possibilité d'extension des cultures

Cette appréciation est essentiellement fondée sur des observations de terrain et ne tient pas compte des droits préexistants susceptibles d'être revendiqués sur les terrains non exploités par l'agriculture.

Cette approche permet également d'apprécier la contribution éventuelle que la mise en place effective du mécanisme de PSE pourrait apporter en vue de la réalisation des investissements agricoles permettant d'accompagner le changement de système de production des agriculteurs.

Le calcul de la capacité de financement théoriquement dégagée par la mise en place du PSE

Ce calcul est fondé sur le tableau de recettes et dépenses de la CU d'Andapa au regard de la gestion du réseau de bornes-fontaines. II repose sur l'hypothèse que les fonds générés par la taxation des 24 bornes-fontaines existantes sont effectivement perçus par la commune, et que la recette obtenue permet en moins d'une année d'accroître le réseau jusqu'à l'établissement des 91 bornes prévues. Dans cette perspective, la répartition envisagée dans le cadre de la Plateforme de concertation est la suivante: - $60 \%$ des recettes mensuelles provenant de la taxation des bornes-fontaines devraient être affectées à l'extension et l'entretien du réseau de bornes-fontaines dès la seconde année ; - 33 \% devraient servir à compenser les 32 ménages fournisseurs de services environnementaux ;

- $7 \%$ devraient servir à couvrir les frais de gestion de la Plateforme de concertation.

La part qui devait initialement revenir à la commune issue de la taxe prélevée par la Jirama sur les factures de consommation des usagers du réseau d'adduction d'eau potable de la ville d'Andapa n'a pas été prise en considération dans les calculs.

13 Le seuil de survie est un niveau de revenus au-dessous duquel un ménage est considéré comme pauvre. Ce seuil prend des valeurs différentes selon que les pays sont qualifiés de pays développés ou de pays en développement. Dans ce travail, le seuil pris est celui fixé par la Banque mondiale en 1995 pour Madagascar (http://fr.wikipedia.org/wiki/Seuil_de_pauvreté http://donnees.banquemondiale.org/theme/pauvrete - 15/05/2012). 


\section{Résultats}

\section{Logiques comportementales des usagers du sol en amont du bassin versant}

\section{Typologie des ménages avant l'abandon du tavy}

L'analyse factorielle discriminante a permis de classer les usagers du sol en cinq groupes avant que ne soit imposée l'interdiction du tavy sur les sommets protégés (figure 5). Le tableau I indique la répartition des ménages selon différentes caractéristiques : les ménages autochtones (G1) et les ménages migrants (G5) pratiquent essentiellement le tavy ; toutefois, les premiers ont davantage accès aux bas-fonds sans en être propriétaires. Les autres groupes investissent de manière diversifiée dans l'exploitation des basfonds (riziculture dominante pour les ménages du G2), des cultures pérennes (cultures dominantes pour les ménages du G4), et/ou le salariat agricole (activité dominante pour les ménages du G3).

\section{Typologie des ménages après l'abandon du tavy}

Alors que les paiements prévus n'ont pas été effectués, l'interdiction de la culture sur brûlis sur les sommets protégés a engendré une modification substantielle des comportements des agriculteurs qui se répartissent une année après la signature du contrat de PSE en trois catégories (figure 6).

Le tableau II présente la répartition des ménages de la typologie 1 dans les trois groupes identifiés après l'abandon de la culture sur brûlis (tavy):

- M1, difficulté d'adaptation à l'interdiction de la culture sur brûlis (25\%) ;

- M2, adaptation mitigée à l'interdiction de la culture sur brûlis (62,5\%) ;

- M3, adaptation aisée à l'interdiction de la culture sur brûlis (12,5\%).

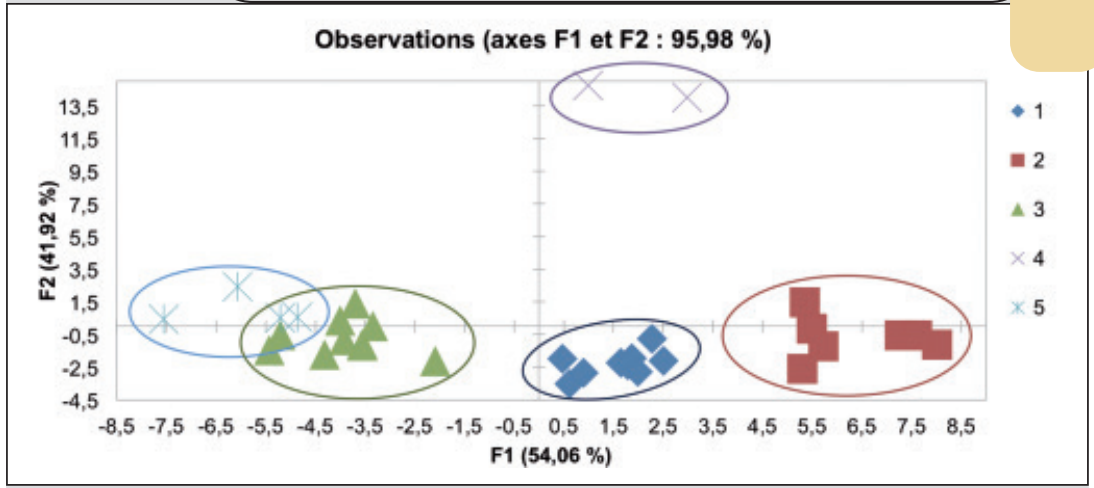

Figure 5.

Profil des ménages avant l'abandon du tavy.

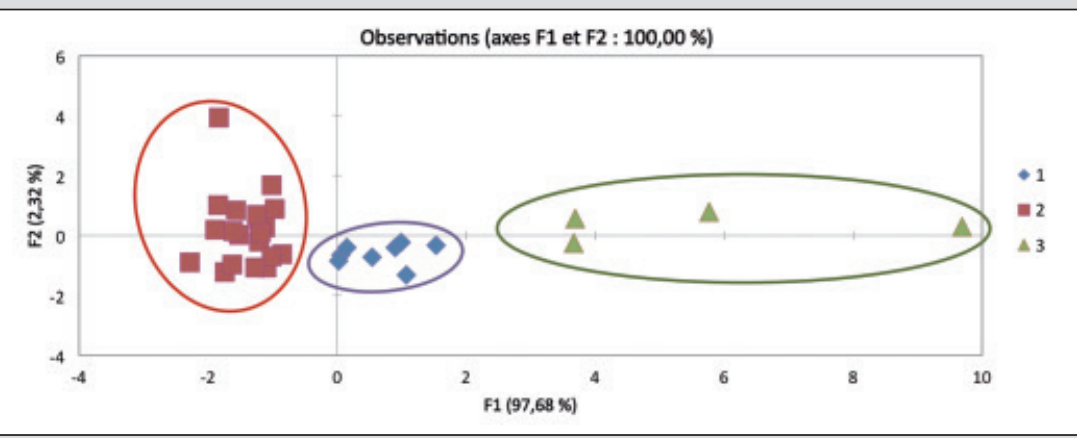

Figure 6

Profil des ménages après l'abandon du tavy.

Tableau I.

Synthèse des caractéristiques des ménages avant l'abandon du tavy.

\begin{tabular}{|c|c|c|c|c|c|c|}
\hline Groupe & G1 & G2 & G3 & G4 & G5 & Total \\
\hline $\begin{array}{l}\text { Caractéristiques } \\
\text { globales }\end{array}$ & $\begin{array}{l}\text { Usagers disposant } \\
\text { de surfaces de tavy } \\
(1,4 \mathrm{ha})>\text { ou }=\text { au } \\
\text { bas-fond }(1,15 \mathrm{ha})\end{array}$ & $\begin{array}{l}\text { Usagers disposant } \\
\text { de bas-fond ( } 2 \text { ha }) \\
\text { largement > au tavy } \\
(0,9 \text { ha })\end{array}$ & $\begin{array}{l}\text { Usagers de terrains } \\
\text { de petite superficie } \\
\text { ( } 0,5 \text { ha), salariés } \\
\text { agricoles }\end{array}$ & $\begin{array}{l}\text { Usagers de plus } \\
\text { de } 4,5 \text { ha de } \\
\text { terres en amont }\end{array}$ & $\begin{array}{c}\text { Usagers migrants pratiquant } \\
\text { essentiellement le tavy sur } \\
1,7 \text { ha, avec peu d'accès au } \\
\text { bas-fond ( } 0,33 \text { ha) }\end{array}$ & \\
\hline \multirow{2}{*}{$\begin{array}{r}\text { Ménages Effectifs } \\
\%\end{array}$} & 9 & 7 & 10 & 2 & 4 & 32 \\
\hline & 28 & 22 & 31 & 6 & 13 & 100 \\
\hline \multirow{2}{*}{$\begin{array}{l}\text { Modes d'acquisition } \\
\text { des terres sur bas- } \\
\text { fonds }\end{array}$} & $\begin{array}{l}\text { Métayage et/ou } \\
\text { fermage (93\%) }\end{array}$ & $\begin{array}{l}\text { Métayage et/ou } \\
\text { fermage (74\%) }\end{array}$ & $\begin{array}{l}\text { Métayage et/ou } \\
\text { fermage (60\%) }\end{array}$ & $\begin{array}{l}\text { Métayage et/ou } \\
\text { fermage (100\%) }\end{array}$ & $\begin{array}{l}\text { Métayage et/ou } \\
\text { fermage (100\%) }\end{array}$ & \\
\hline & Achat (7 \%) & Héritage (26\%) & $\begin{array}{l}\text { Héritage (23\%) } \\
\text { Achat (17\%) }\end{array}$ & & & \\
\hline $\begin{array}{l}\text { Caractéristiques } \\
\text { sociales }\end{array}$ & & \multicolumn{2}{|c|}{ Essentiellement autochtones } & & Migrants & \\
\hline
\end{tabular}


Tableau II.

Répartition des ménages de la typologie 1 (G1 à G5) avant l'interdiction du tavy dans la typologie 2 (M1 à M3) élaborée une année après l'interdiction du tavy.

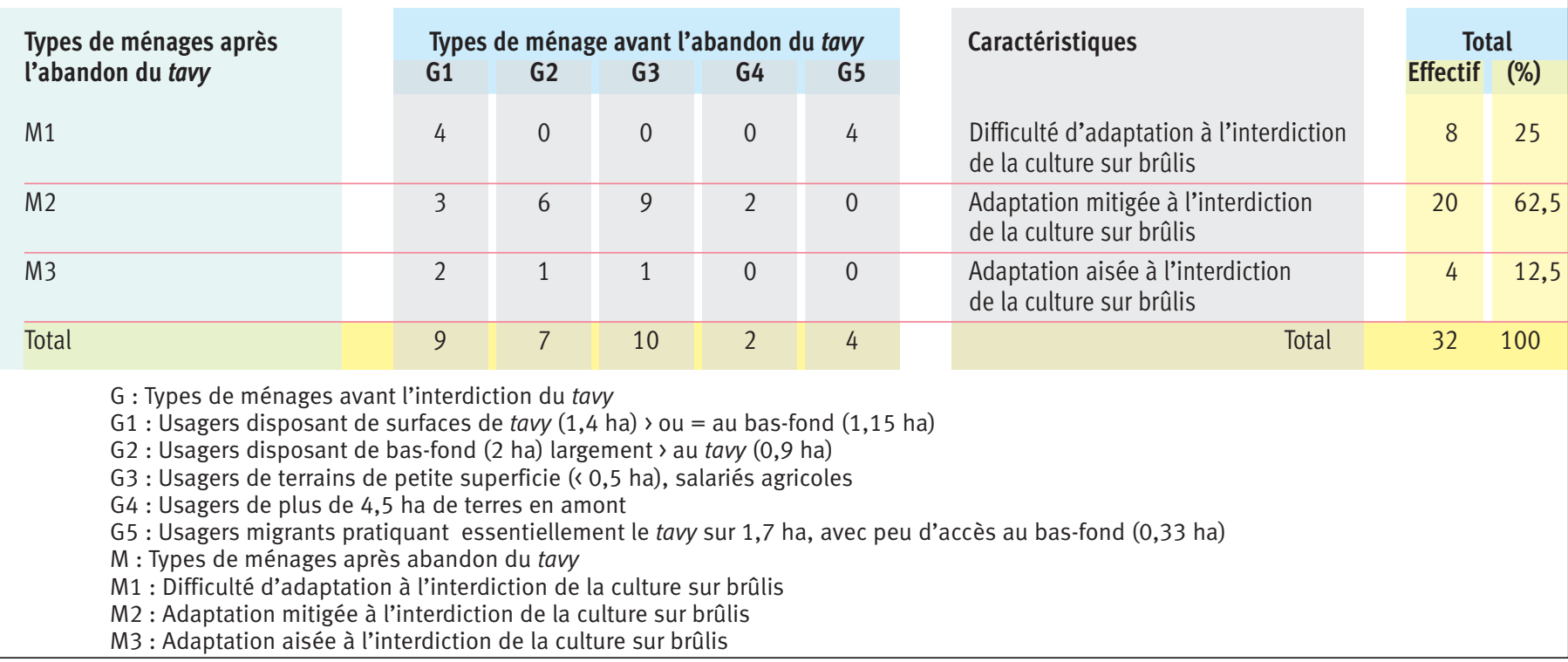

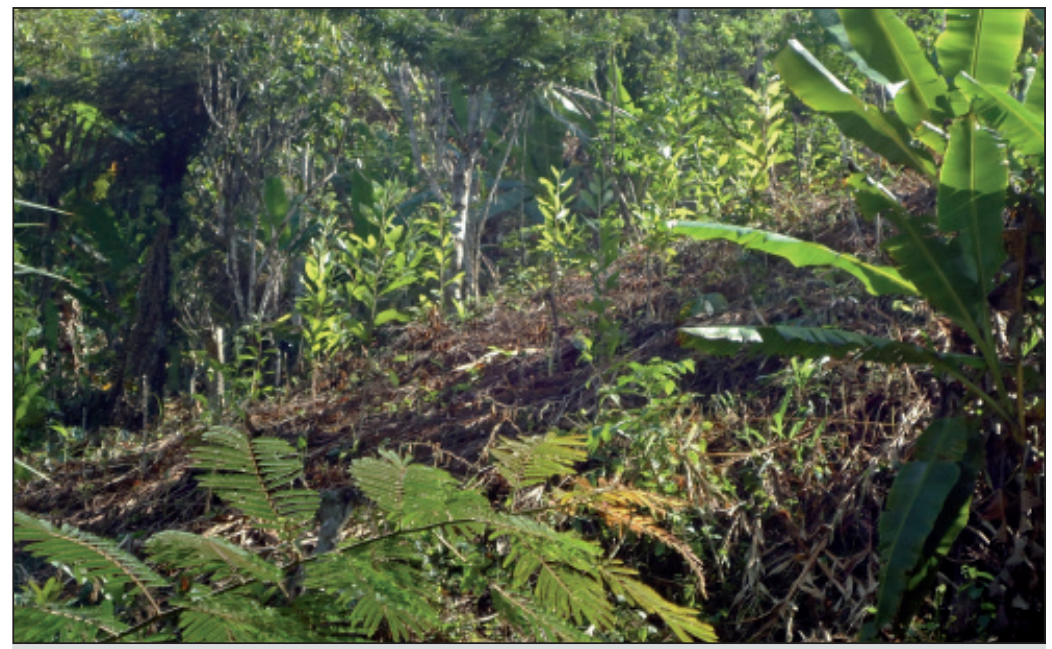

Photo 3.

Reboisement de jeunes plants d'acacia comme cultures pérennes dans les sommets protégés. Photo M. Rakotondrabe.
Tendances d'évolution des comportements des ménages avant et après l'abandon du tavy

Avant l'abandon effectif du tavy, la répartition des cultures dans les différents espaces de production constituait une stratégie commune à l'ensemble des cinq types identifiés et permettant de stabiliser les surfaces affectées à la culture sur brûlis forestier (figure 7).

Cependant, si après l'interdiction les trois types identifiés s'investissent la première année dans l'extension des cultures pérennes et la diminution des cultures annuelles ${ }^{15}$, la reprise des pratiques de culture sur brûlis forestier s'effectue rapidement (figure 8).

15 À partir de 2010, plus aucun ménage n'a brûlé de parcelles sur la zone de protection de 42 ha. Cependant, certains ont encore cultivé les zones précédemment défrichées sans recourir au brûlis. On note une moyenne de réduction de $74 \%$ des superficies destinées aux cultures sur brûlis pour les 32 ménages concernés.

\begin{tabular}{|c|c|c|c|c|c|c|c|c|c|c|c|c|c|c|c|c|c|c|c|c|c|c|c|c|c|c|c|c|c|}
\hline \multirow{2}{*}{ 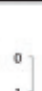 } & \multicolumn{5}{|c|}{ Groupe 1} & \multicolumn{6}{|c|}{ Groupe 2} & \multicolumn{6}{|c|}{ Growpe 3} & \multicolumn{6}{|c|}{ Groupe 4} & \multicolumn{6}{|c|}{ Groupe 5} \\
\hline & $C P$ & $\mathrm{CA}$ & BF & $v$ & $\mathbb{E}$ & 0 & $C P$ & ca & BF & v & ZNP & 0 & $C P$ & $C A$ & BF & $v$ & ZNP & 0 & $C P$ & $\mathrm{CA}$ & & v & ZNP & 0 & $C P$ & ca & $B F$ & v & ZNP \\
\hline 1 & - & $\Theta$ & 0 & • & & 1. & • & 0 & 0 & . & & 1 & 0 & 0 & $\bullet$ & $\cdot$ & $\cdot$ & 1 & 0 & 0 & . & & & 1. & • & 0 & • & & . \\
\hline 2 & $\bullet$ & 0 & 0 & - & $\cdot$ & 2 & - & 0 & 0 & • & $\cdot$ & 2 & 0 & 0 & $\bullet$ & • & $\cdot$ & 2 & 0 & 0 & . & & . & 2. & - & 0 & • & · & • \\
\hline 3 & 0 & 0 & 0 & 0 & • & 3 & - & 0 & 0 & $\bullet$ & • & 3 & 0 & 0 & $\bullet$ & 0 & • & 3 & 0 & 0 & $\cdot$ & $\cdot$ & $\cdot$ & 3 & 0 & 0 & • & • & • \\
\hline 4 & 0 & 0 & 0 & 0 & $\bullet$ & 4. & 0 & 0 & 0 & - & • & 4 & 0 & 0 & $\bullet$ & 0 & • & 4 & 0 & 0 & • & • & • & 4. & 0 & 0 & • & • & • \\
\hline 5 & 0 & 0 & 0 & 0 & • & $\frac{e^{5}}{\varepsilon^{5}}$ & - & 0 & 0 & • & • & $\frac{p^{5}}{\varepsilon^{5}}$ & 0 & 0 & $\bullet$ & 0 & • & $i^{5}$ & 0 & 0 & • & • & • & $y^{5}$ & 0 & 0 & - & - & • \\
\hline 6. & 0 & 0 & 0 & 0 & • & $\xi_{6}$ & - & 0 & • & ○ & • & $\xi_{6}$ & 0 & 0 & $\bullet$ & 0 & • & 86 & 0 & 0 & • & • & - & 56. & ○ & 0 & • & - & • \\
\hline 7 & 0 & 0 & 0 & 0 & • & T & - & 0 & - & 0 & • & 7. & 0 & 0 & • & 0 & - & , & 0 & 0 & $\bullet$ & • & - & 7 & o & 0 & • & - & - \\
\hline 8 & 0 & 0 & 0 & 0 & • & 8 & 0 & 0 & 0 & 0 & • & 8 & 0 & 0 & 0 & 0 & • & 8 & 0 & 0 & • & • & • & 8 & • & 0 & • & $\bullet$ & • \\
\hline 9 & 0 & 0 & 0 & 0 & $\bullet$ & , & 0 & 0 & 0 & 0 & • & 9 & 0 & 0 & - & 0 & • & 9. & 0 & 0 & • & • & • & 9 & 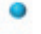 & 0 & • & • & • \\
\hline 10 & 0 & 0 & 0 & 0 & $\bullet$ & 10 & - & 0 & 0 & 0 & • & 10 & 0 & 0 & ○ & 0 & • & 10 & 0 & ○ & $\bullet$ & $\bullet$ & • & 10 & $\bullet$ & 0 & $\bullet$ & $\bullet$ & • \\
\hline
\end{tabular}

Figure 7.

Évolution de la répartition des surfaces couvertes par l'ensemble des agriculteurs d'un même groupe avant l'abandon du tavy. CP : cultures pérennes ; CA : cultures annuelles ; BF : bas-fonds ; V : versants ; ZNP : sommets non protégés. 
Tableau III.

Superficie agricole (en ha) à prévoir par catégorie de bassin de production selon la projection sur 10 ans.

\begin{tabular}{|c|c|c|c|c|c|c|}
\hline \multirow{5}{*}{ Année 1} & & CP & CA & v & ZNP & $\mathrm{BF}$ \\
\hline & M1 & 4,64 & 0,2 & 0,31 & 0,25 & 0,9 \\
\hline & M2 & 1,97 & 0,46 & 0,26 & 0,21 & 0,78 \\
\hline & M3 & 11,17 & 0,36 & 0,10 & 0,10 & 1,00 \\
\hline & Total & 17,78 & 1,02 & 0,67 & 0,56 & 2,68 \\
\hline \multirow[t]{5}{*}{ Année 10} & M1 & 13,23 & 2,38 & 5,65 & 4,62 & 19,60 \\
\hline & M2 & 10,71 & 1,46 & 7,19 & 6,77 & 31,33 \\
\hline & M3 & 14,08 & 0,60 & 4,95 & 5,18 & 17,26 \\
\hline & Total & 38,02 & 4,44 & 17,79 & 16,57 & 68,19 \\
\hline & Disponibilité des terres & ++ & + & ++ & +++ & + \\
\hline
\end{tabular}

$\mathrm{CP}$ : Cultures pérennes ; ZNP : Sommets non protégés ; V : Versants

$\mathrm{CA}$ : Cultures annuelles; $\mathrm{BF}$ : Bas-fonds

\section{Comparaison des états financiers des usagers du sol avant et après l'abandon du tavy}

En comparant les états financiers des ménages, une augmentation du taux de rentabilité interne (TRI) est constatée après l'abandon du tavy (figure 9). On observe une augmentation des revenus agricoles des ménages et une baisse de leur autoconsommation (en \$US/jour/personne) après interdiction du tavy (figure 10).

\section{L’importance relative des investissements nécessaires pour pérenniser les changements de comportement des ménages exploitants}

Compte tenu de l'accroissement de la population, si les pratiques agricoles ne changent pas, et si aucune intensification de la production n'est engagée, les besoins en superficie des 32 ménages considérés les conduiront à s’approprier dans les dix années à venir des espaces agricoles considérables (tableau III).

L'aménagement de nouvelles terres cultivables et l'intensification des systèmes de culture est donc nécessaire dans chacun des espaces de production investis par les agriculteurs pour éviter un retour à la défriche forestière. Pour satisfaire ces besoins, le mécanisme de PSE, s’il était effectivement fonctionnel, permettrait de dégager une somme annuelle moyenne de 234733000 MGA (70 069 euros) pour offrir une compensation aux 32 ménages concernés par l'étude.

Ce produit, destiné à dédommager les fournisseurs de services, est comparé aux autres coûts induits par la mise en place des PSE (figure 11). Il en découle que les coûts d'opportunité liés à l'abandon de la déforestation par les

\begin{tabular}{|c|c|c|c|c|c|c|c|c|c|c|c|c|c|c|c|c|c|}
\hline \multicolumn{6}{|c|}{ Merage 1} & \multicolumn{6}{|c|}{ Menage 2} & \multicolumn{6}{|c|}{ Monase 3} \\
\hline 0 & $C P$ & $c a$ & $B F$ & $v$ & ZNP & 0 & 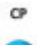 & $C A$ & $B F$ & $v$ & ZNP & 0 & $C P$ & ca & BF & $v$ & ZNP \\
\hline 1 & U & & - & - & $\cdot$ & 1 & 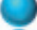 & - & 0 & - & - & 1 & U & & & & $\cdot$ \\
\hline 2 & 0 & • & - & - & $\cdot$ & 2 & 0 & - & 0 & - & - & 2 & 0 & . & & & $\bullet$ \\
\hline 3 & 0 & * & 0 & - & • & 3 & 0 & 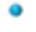 & 0 & • & • & 3 & 0 & • & & & 0 \\
\hline 4 & 0 & - & 0 & - & • & 4 & 0 & 0 & 0 & • & - & 4 & 0 & - & . & . & 0 \\
\hline$\frac{t^{5}}{5}$ & 0 & $\bullet$ & 0 & - & • & c s & 0 & 0 & 0 & • & - & $I^{5}$ & - & • & $\cdot$ & . & 0 \\
\hline$\sum_{6}$ & 0 & $\bullet$ & 0 & - & • & इ。 & 0 & 0 & 0 & - & - & ई 6 & - & $\bullet$ & $\cdot$ & . & 0 \\
\hline 7 & $\bullet$ & $\bullet$ & 0 & • & • & 7 & 0 & 0 & 0 & - & - & 7 & $\bullet$ & - & - & - & 0 \\
\hline 8 & $\bullet$ & $\bullet$ & 0 & - & - & 8 & 0 & 0 & 0 & $\bullet$ & $\bullet$ & 8 & $\bullet$ & • & $\cdot$ & - & 0 \\
\hline 9 & $\bullet$ & • & ○ & - & - & 9 & 0 & 0 & 0 & $\bullet$ & $\bullet$ & 9 & - & • & $\cdot$ & • & $\bullet$ \\
\hline 10 & $\bullet$ & 0 & - & • & - & 10 & $\bullet$ & 0 & 0 & $\bullet$ & $\bullet$ & 10 & - & • & $\cdot$ & • & $\bullet$ \\
\hline 11 & & & & & & 11 & & & & & & 11 & & & & & \\
\hline
\end{tabular}

Figure 8.

Tendances des comportements des ménages après l'abandon du tavy.

$C P$ : cultures pérennes; $C A$ : cultures annuelles ;

$\mathrm{BF}$ : bas-fonds ; $\mathrm{V}$ : versants ; ZNP : sommets non protégées.

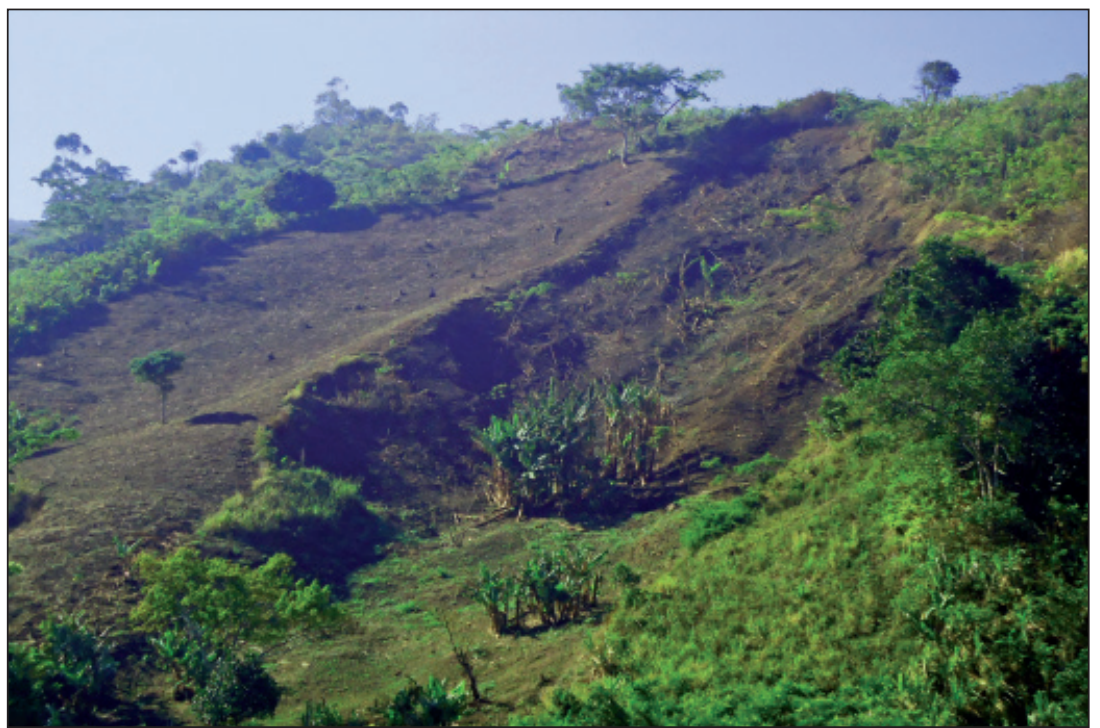

Photo 4.

Surface défrichée (tavy) en amont du bassin versant de Sahamazava, Andapa. Photo M. Rakotondrabe. 


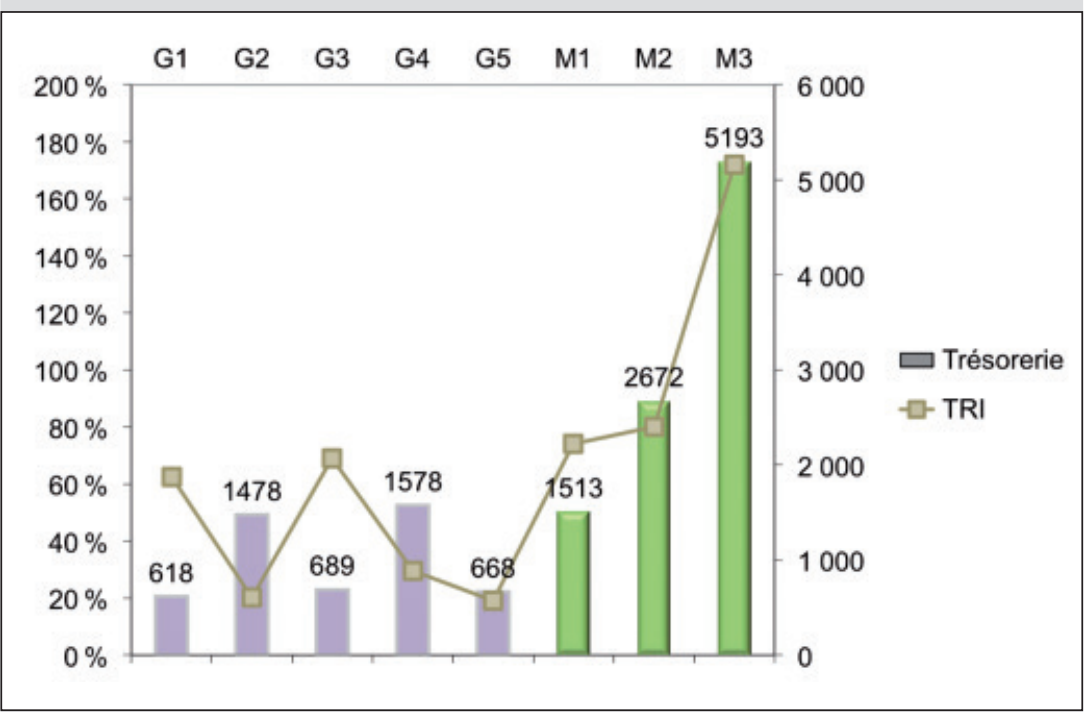

Figure 9.

Comparaison du taux de rentabilité interne (TRI) et de la trésorerie des ménages (1 000 MGA équivalant à $0,30 €$ ou 0,41 US\$) avant et après l'interdiction du tavy.

$\mathrm{G}$ : Types de ménages avant l'interdiction du tavy

G1 : Usagers disposant de surfaces de tavy $(1,4 \mathrm{ha})>$ ou $=$ au bas-fond (1,15 ha)

G2 : Usagers disposant de bas-fond ( 2 ha) largement > au tavy ( $0,9 \mathrm{ha}$ )

$\mathrm{G} 3$ : Usagers de terrains de petite superficie ( $<0,5 \mathrm{ha})$, salariés agricoles G4 : Usagers de plus de 4,5 ha de terres en amont

G5 : Usagers migrants pratiquant essentiellement le tavy sur 1,7 ha, avec peu d'accès au bas-fond ( $0,33 \mathrm{ha})$

$M$ : Types de ménages après abandon du tavy

M1 : Difficulté d'adaptation à l'interdiction de la culture sur brûlis

M2 : Adaptation mitigée à l'interdiction de la culture sur brûlis

M3 : Adaptation aisée à l'interdiction de la culture sur brûlis

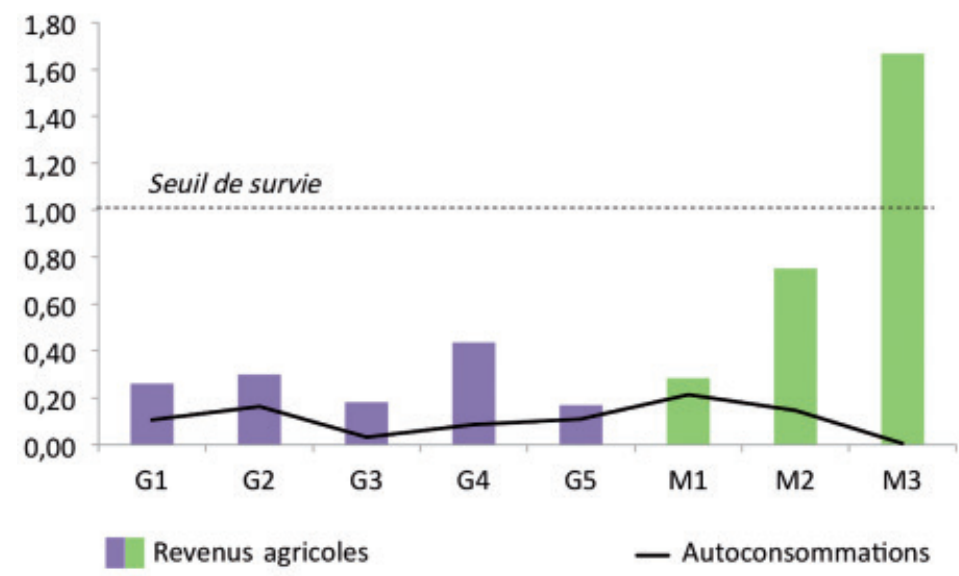

Figure 10.

Revenus agricoles et autoconsommations par rapport au seuil de survie (en US\$/jour/personne). ménages établis en amont du bassin versant sont extrêmement faibles et pourraient être complétés par des sommes substantielles directement affectées aux investissements nécessaires pour aborder un changement durable des systèmes de production.

Dans ces conditions, les investissements requis par les exploitants qui se sont exprimés dans les focus groups pourraient être réalisés grâce à l'évolution substantielle de leur trésorerie (tableau IV) et de leurs revenus agricoles (figure 12).

L'augmentation de la trésorerie devrait pouvoir permettre d'aménager le supplément de terres nécessaires, d'intensifier la production, ou d'investir dans d'autres activités génératrices de revenus. Sans accompagnement personnalisé par type de ménage agricole, il est cependant probable que les écarts se creusent entre les populations les plus vulnérables et celles plus aisées.

\section{Discussion et recommandations}

Seuls les ménages ayant investi dans l'exploitation de cultures pérennes ont réellement pu s'adapter à l'interdiction de la culture sur brûlis forestier initiée dans le cadre de la mise en place du PSE en 2009. Ceux qui étaient très dépendants de l'exploitation des cultures annuelles restent par contre très vulnérables au changement. Pourtant, les agriculteurs exploitant les sommets mis en protection sont dans l'ensemble essentiellement préoccupés par la recherche d'une stabilité économique à moindre risque dans laquelle le facteur foncier occupe une place prépondérante. Cela explique que la simulation des activités agricoles des ménages sur 10 ans montre qu'un retour aux anciennes habitudes de défriche forestière est inévitable si des investissements adaptés aux stratégies des ménages exploitants ne sont pas réalisés à travers le PSE.

Or, la viabilité économique des PSE se heurte dans la réalité à trois obstacles majeurs : les difficultés liées à la sécurisation foncière des espaces agricoles et forestiers ; les dysfonctionnements de l'économie de marché en zone rurale reculée ; les blocages institutionnels.

Dans ce contexte, les porteurs de projets visant la mise en place de PSE pour contenir l'extension des surfaces de culture sur brûlis forestier devraient adapter leurs interventions pour faciliter la nécessaire transformation des systèmes de production. 
Tableau IV.

Trésorerie moyenne annuelle des ménages sur 10 ans sans et avec les compensations liées au mécanisme PSE.

\begin{tabular}{|c|c|c|c|c|}
\hline & M1 & M2 & M3 & $\begin{array}{l}\text { Total pour les } \\
32 \text { ménages (euros) }\end{array}$ \\
\hline Nombre de ménages & 8 & 20 & 4 & 32 \\
\hline $\begin{array}{l}\text { Trésorerie après l'interdiction effective du tavy } \\
\text { sans les compensations (euros /ménage/an) }\end{array}$ & 56 & 40 & 387 & $2796^{1}$ \\
\hline $\begin{array}{l}\text { Trésorerie simulée avec les } \\
\text { compensations }^{3} \text { (euros/ménage/an) }\end{array}$ & 226 & 102 & 768 & $6920^{2}$ \\
\hline Pourcentage d'augmentation & 75 & 61 & 50 & \\
\hline
\end{tabular}

\section{Des obstacles incontournables entravant la mise en place des PSE à Madagascar}

\section{Des difficultés liées à la sécurisation des espaces agricoles et forestiers}

Étant le support de toutes les ressources, le foncier tient une place importante dans les stratégies des ménages agricoles. La raréfaction des basfonds cultivables entraîne une course effrénée à la recherche de terres fertiles dans les forêts avoisinantes. Ce phénomène est amplifié par l'accroissement rapide de la population ${ }^{16}$. Par ailleurs, la forêt est traditionnellement considérée comme un héritage des ancêtres, et souvent associée à une "réserve foncière » dont l'accès et l'usage sont régis par les autorités coutumières (ray aman-dreny), auxquelles sont généralement soumis les autochtones, mais pas toujours les migrants.

La conservation des ressources naturelles repose en conséquence sur la sécurisation foncière des agriculteurs et la reconnaissance des prérogatives des communautés de base. En effet, au travers des contrats de transfert de gestion des ressources forestières de l'État aux populations locales (contrats de TGRNR localisés sur la figure 2), ces dernières sont légalement investies de la régulation de l'accès aux forêts et de l'usage des ressources naturelles (Aubert, 2013). Dans ce contexte, les PSE doivent être :

- efficaces, grâce à une sécurisation foncière des ménages exploitants (Grieg-Gran et al., 2005) qui investissent dans des aménagements pérennes en respect des cahiers des charges annexés aux contrats de transfert de gestion ;

- efficients, au regard de l'accès et de l'allocation des compensations financières prévues, le cas échéant, en association avec un dispositif de microcrédit adéquat (Rasoloarison et al., 2001) et un accompagnement subséquent garantissant la formation aux techniques culturales écologiquement et économiquement durables (Lavigne Delville, 1997) ;

16 Outre une croissance démographique de l'ordre de $3 \%$ prise en considération dans les calculs, l'arrivée continue de migrants a été régulièrement observée depuis 1990.

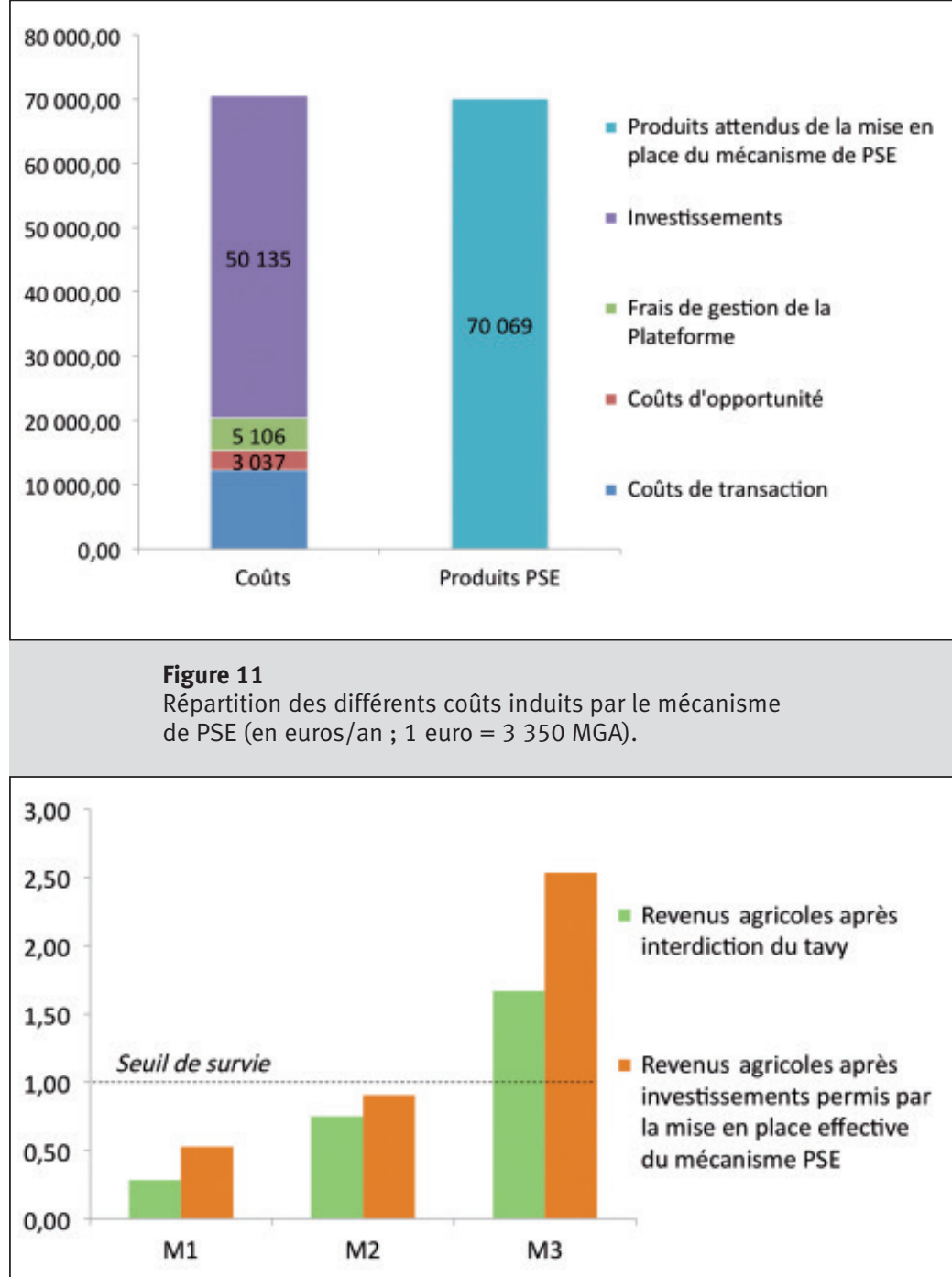

Figure 12.

Augmentation du revenu agricole des usagers du sol (en US\$/jour/personne).

M1 : Difficulté d'adaptation à l'interdiction de la culture sur brûlis ; M2 : Adaptation mitigée à l'interdiction de la culture sur brûlis ; M3 : Adaptation aisée à l'interdiction de la culture sur brûlis. 


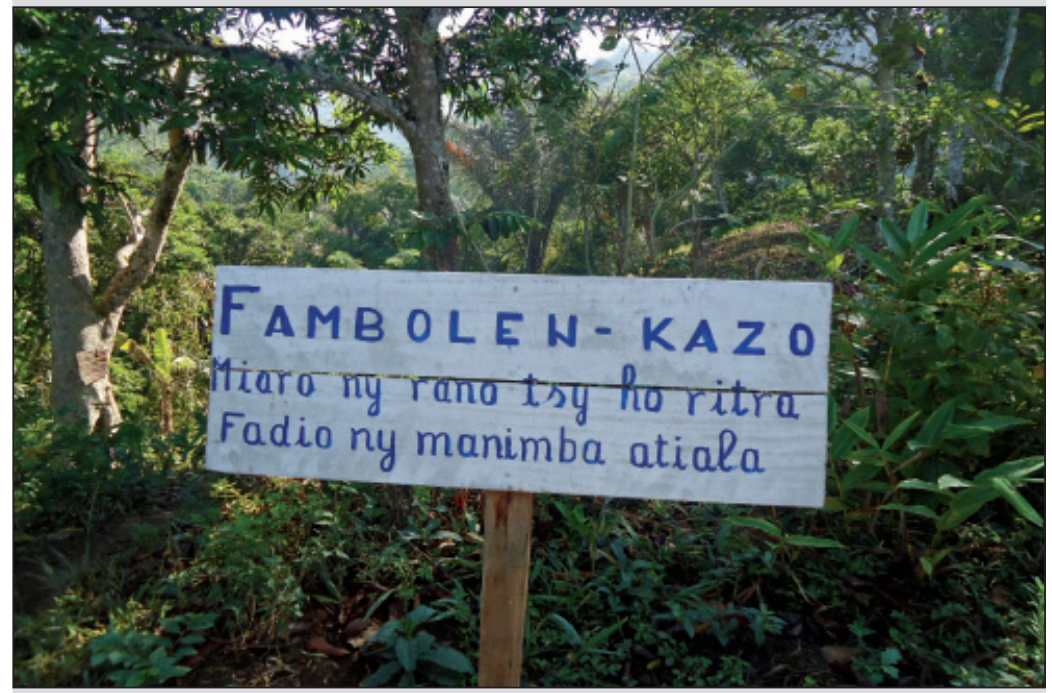

Photo 5.

Panneau de sensibilisation de la population locale à l'entrée de la zone de protection. (Traduction : le reboisement, garant de la protection des ressources en eau; ne pas détruire la forêt.)

Photo M. Rakotondrabe.

\section{Blocages institutionnels}

Les compensations promises par le projet n'ont toujours pas été distribuées aux agriculteurs deux ans après le lancement du PSE, provoquant un découragement social et un probable « retour en masse » dans les forêts pourtant protégées. Cette situation est fréquemment rencontrée à Madagascar du fait que le contexte institutionnel ne facilite ni l'établissement de circuits financiers courts, ni la sécurisation des transactions financières (Ramamonjisoa, 2009).

En effet, les PSE ne sont pas inscrits au sein d'une politique publique, à l'instar du Costa Rica ou du Brésil (Randrianarison et Karpe, 2010), mais sont généralement portés par des organismes de conservation de la nature (Cahen-Fourot, 2011). Dans ce contexte, les coûts de transaction sont particulièrement conséquents et les besoins immédiats ou les aspirations des ménages exploitants fournisseurs de services environnementaux ne sont que très rarement appréciés à leur juste valeur. Face à leur divergence d'intérêts, les parties prenantes du PSE (fournisseurs et acheteurs de services, organismes d'appui et intermédiaires) ne parviennent pas à conjuguer équité, par la satisfaction des besoins - équitables, au minimum au regard du respect des normes portées par les coutumes, les usages et les règlements visà-vis de l'accès aux terrains forestiers, aux terrains agricoles et à l'eau (Razafiarijaona, 2005) ; au mieux, en envisageant une redistribution adaptée prenant en considération les besoins des populations les plus vulnérables, qui généralement sont aussi les plus actives dans l'exercice des pressions anthropiques sur les écosystèmes forestiers (Mayrand et Paquin, 2004).

\section{Difficultés liées à l'accès et à la fluctuation des marchés}

Madagascar est l'un des plus grands consommateurs de riz par habitant. La riziculture constitue la première source de revenus des habitants d'Andapa ; les fluctuations des marchés des produits issus des cultures de rente incitent souvent les agriculteurs à se retrancher sur l'acquisition de nouvelles terres en exerçant le droit coutumier de « première hache $»$.

C'est pourquoi l'abandon de la défriche sur brûlis forestier ne séduit que 12,5\% des ménages (M3) recensés au sein de la zone cible de la protection posée dans le cadre du mécanisme de PSE institué à Andapa. L'absence d'un marché stable et permanent des produits des cultures pérennes implique, pour ceux qui renonceraient totalement aux cultures annuelles, une dépendance risquée aux fluctuations des marchés, incluant même la possibilité de devoir à un moment donné vendre leurs produits à perte. La pratique du tavy est donc issue d'un choix économiquement judicieux, bien que peu rentable, justifié par une prise de risque minimum (Bertrand et Lemalade, 2003). réels des fournisseurs de services, et efficacité, par la conservation effective des services écosystémiques (Karsenty et al., 2009) ; ce qui déstabilise le fondement du mécanisme, comme l'illustre la fréquente remise en cause du caractère volontaire des contrats.

Par ailleurs, un des blocages lié au versement des compensations prévues aux ménages exploitant la zone placée sous protection sur le bassin versant de Sahamazava est le refus de la Jirama de payer les surtaxes sur fonds de travaux (40\%) qui devraient être reversées à la CU. En effet, l'Autorité nationale de l'eau et de l'assainissement (Andea), par le biais du Fonds national de la ressource en eau (FNRE), ment servir à financer les projets impliquant la mise en œuvre de PSE-Eau (Andriamahefazafy, 2011 ; Cahen-Fourot, 2011). La Jirama considère qu'en s'investissant directement dans le mécanisme de PSE elle paierait deux fois pour le même service. Ce problème est rencontré par d'autres projets qui investissent dans la mise en place de PSE-Eau, tel celui d'Antarambiby (Fianarantsoa), où l'interaction entre la population locale et la branche régionale de la Jirama est quasi inexistante (Andriamahefazafy, 2011).

Ces faits témoignent des difficultés de la mise en œuvre de mécanismes de PSE dans un pays en développement. Toutefois, la mise en place d'une plateforme de concertation à Andapa a permis d'engager le dialogue entre la Jirama, les ménages exploitants et les citadins ; bien que les PSE ne respectent pas à Madagascar les termes de la définition canonique posée par Wunder (2005), ce mécanisme pourrait contribuer à promouvoir le développement durable. perçoit déjà une cotisation de la Jirama qui devrait précisé- 


\section{Les modalités de PSE « Investissement » ou asset-building}

Au regard des analyses réalisées, certaines recommandations peuvent être faites aux promoteurs de projets investis dans des mécanismes de PSE visant l'appropriation de modes de production compatibles avec les services écosystémiques.

\section{Promouvoir l'établissement préalable et systématique de diagnostics socio-fonciers des systèmes agraires}

La connaissance très partielle des réalités locales des différentes initiatives de développement émanant de l'État et/ou des organisations non gouvernementales constitue un des principaux blocages du développement rural à Madagascar. L'établissement de diagnostics socio-fonciers et l'analyse de la situation économique des ménages avant la mise en œuvre du PSE sont primordiaux, notamment dans le but de garantir la viabilité des mécanismes de financement envisagés. Aussi, inciter et reconnaître les arrangements institutionnels locaux prônant la légitimité de droits sur les ressources permet aux acteurs de jouir réellement de la liberté de gérer eux-mêmes ces dernières, et de sécuriser l'accès et l'usage du foncier; il faudrait alors favoriser une régulation sociale reposant sur le respect des règles coutumières, contractuelles et légales localement appropriées et/ou appropriables (Razafiarijaona, 2005).

\section{Considérer les besoins en investissement plutôt que les coûts d'opportunité pour faire évoluer les systèmes de production}

La mise en place d'un PSE-Investissement vise à établir, par le jeu de flux financiers courts, la garantie d'une gestion durable des ressources naturelles. Les paiements, associés le cas échéant à d'autres sources de financement complémentaires, pourraient permettre aux fournisseurs de services d'investir dans :

- la redynamisation des marchés de produits agricoles, voire forestiers, à travers l'établissement d'un réseau de commercialisation (cas du Programme de paiement agroenvironnemental à l'échelle communale au Cambodge ; Clements et al., 2010); - l'aménagement et la sécurisation foncière subséquente des espaces de production (Toillier, 2011), dont le bas-fond qui constitue un élément essentiel ;

- la vulgarisation de pratiques agricoles alternatives au tavy et de l'agriculture durable (cas de la mise en place du Fondo de Protección del Agua, Fonag, en Équateur) (Landell-Mills et Porras, 2002).

\section{Renforcer les capacités des acteurs}

Dans cette perspective, les PSE sont des mécanismes qui interviennent en complément des autres instruments de politique publique pour renforcer les actions en faveur de la gestion durable des services écosystémiques. En ce sens, l'un de leurs principaux intérêts est d'envisager de nouvelles relations entre des acteurs qui, peut-être, ne disposaient pas encore d'espace de négociation pour tenter de faire converger leurs intérêts respectifs. Afin que le mécanisme de PSE participe à l'émergence de relations gagnantgagnant (Fisher et al., 2010), il apparaît essentiel d'inscrire les actions qui visent son institution dans:
- le renforcement des capacités de négociation des acteurs afin de leur permettre de mieux argumenter sur la prise en compte, par les porteurs de projets de développement ou de conservation, de leurs besoins effectifs et de leurs aspirations (Andriamahefazafy, 2011 ; Laurans et al., 2011) ; - la promotion d'une représentativité légitime de l'ensemble des acteurs impliqués au sein des structures de gestion des ressources naturelles (y compris agricoles) intervenant sur le territoire considéré ;

- la recherche de la participation de tous les acteurs (Toillier, 2011), notamment des plus pauvres, marginalisés par le système, afin d'éviter la relocalisation des pratiques de tavy vers les forêts environnantes (Karsenty et al., 2009) ;

- la communication et/ou la formation ${ }^{17}$ des parties prenantes sur les règlements et la législation en vigueur.

\section{Conclusion}

Le mécanisme PSE-Eau initié à Andapa a engendré des changements de pratiques chez les agriculteurs qui cultivaient dans le périmètre de protection des sources alimentant la commune urbaine en eau potable. En 2009, la plupart des ménages suivaient les directives du projet promoteur du PSE en abandonnant le tavy et en investissant dans les cultures pérennes. Toutefois, il est apparu que les changements de comportement ne permettaient pas aux agriculteurs de s'affranchir de logiques sociales et économiques propres non considérées par le mécanisme. La modélisation réalisée à partir de données de terrain sur un échantillon exhaustif d'agriculteurs fournisseurs de services environnementaux révèle, au bout de quelques années de simulation, un retour aux anciennes habitudes de défriche.

Pour la majorité des ménages, malgré le fait que le développement de cultures pérennes pourrait s'avérer rentable, l'abandon de la culture sur brûlis forestier les exposerait trop fortement aux aléas du marché des produits des cultures de rente. D'autres paramètres entravent également les changements de comportement attendus tels que la saturation actuelle des bas-fonds exploitables et le prix locatif élevé des terrains agricoles. Ces constats ouvrent des pistes d'action pour la mise en place de PSE-Investissement intégrés aux autres instruments de politiques publiques, qui, à partir de la création de flux financiers courts, pourraient permettre des investissements dans les infrastructures de base et la formation, éléments indispensables à la conservation des forêts de Madagascar, même protégées.

\section{Remerciements}

Cette recherche est une partie du projet PESMIX, financée par l'Agence nationale française pour la recherche (convention ANR-10-STRA-008).

17 Rares sont en effet les ménages agricoles qui disposent d'une réelle connaissance des textes en vigueur (forestiers, fonciers, code de l'eau...). Les notables et les fonctionnaires utilisent souvent ces lacunes pour s'accaparer des terrains domaniaux et les faire titrer à leur nom, sans que les villageois puissent intervenir. Aussi faudrait-il renforcer la sensibilisation des acteurs à travers l'audiovisuel (notamment la radio) et susciter des débats publics. 


\section{Références bibliographiques}

ANDRIAMAHEFAZAFY F., MERAL P., RAKOTOJAONA J. R., 2007. Bilan et perspectives de la planification environnementale malgache. In : Chaboud C. et al. (éds). Madagascar face aux enjeux du développement durable : des politiques environnementales à l'action collective locale. Paris, France, Karthala/MAEE, 23-50.

ANDRIAMAHEFAZAFY F., 2011. Expériences des projets pilotes WWF en paiement pour services environnementaux hydrologiques : Eau potable à Fianarantsoa (Bassin versant d'Antarambiby) et à Andapa (Bassin versant de Sahamazava) et écosystèmes de mangroves à Toliara (Site d'Ambondrolava). Antananarivo, Madagascar, WWF, C3EDM, Serena, 43 p.

AUBERT S., 2013, Le processus de sécurisation foncière à partir des relations que les hommes entretiennent entre eux à propos de la terre. Application à la forêt malgache d'Ambohilero. In : Le Roy E. (éd.). La terre et l'homme : Espaces et ressources convoités, entre le local et le glocal. Actes du Congrès d'ISAIDAT-SIRD. Paris, France, Karthala, 87-112.

AUBERT S., RAZAFIARISON S., 2003. Culture sur brûlis et régression des surfaces boisées. In : Aubert S., Razafiarison S., Bertand A. (éds). Déforestation et systèmes agraires à Madagascar : les dynamiques des tavy sur la côte orientale. Montpellier, France, Cirad, 35-51.

BERTRAND A., LEMALADE J.-L., 2003. Riziculture de tavy et sécurité alimentaire. In : Aubert S., Razafiarison S., Bertrand A. (éds). Déforestation et systèmes agraires à Madagascar : les dynamiques des tavy sur la côte orientale. Montpellier, France, Cirad, 75-88.

BRUIJNZEEL S., SWALLOW B., VAN NOORDWIJK M., 2008. Deforestation and the multiple functions of tropical watersheds: are tropical forests indispensable for regulating rainfall and ensuring clean and reliable water supplies? Nairobi, Kenya, ASB, Partnerships for the Tropical Forest Margins, ASB Policy Brief $n^{\circ} 8,4 \mathrm{p}$.

Projet Bassins Versants-Périmètres Irrigués (BVPI) et Aménagement durable du sol, 2006. Évaluation environnementale et sociale régionale, Site de Andapa. BRL Ingénierie. Antanarivo, Madagascar, BRL Madagascar, $244 \mathrm{p}$.

CAHEN-FOUROT L., 2011. L'analyse institutionnaliste des mécanismes de gouvernance des paiements pour services environnementaux à travers la notion de coûts de transaction. Le cas des PSE d'Antamrabiby, d'Andapa et de Honko à Madagascar. Mémoire de mastère 2 du Centre d'études et de recherches pour le développement international (Cerdi), Université d'Auvergne-Clermont-Ferrand I, 127 p.

CARRET J. C., RAJAONSON B., FENO P. J., BRAND J., 2009. L'environnement à Madagascar : un atout à préserver, des enjeux à maîtriser. Antananarivo, Madagascar, Note de la Banque mondiale. [Online] http://www.worldbank.org/content/dam/Worldbank/document/Africa/Madagascar/Report/m adagascar-report-cea-april-2013.pdf

CLEMENTS T., JOHN A., NIELSEN K., TAN S., MILNER-GULLAND E. J., 2010. Payments for biodiversity conservation in the context of weak institutions: Comparison of three programs from Cambodia. Ecological Economics, 69 (6): 1283-1291.
FISHER B., KULINDWA K., MWANYOKA I., TURNER R. K., BURGESS N., 2010. Common pool resource management and PES: Lessons and constraints for water PES in Tanzania. Ecological Economics, 69 (6): 1253-1261.

GRIEG-GRAN M., PORRAS I., WUNDER S., 2005. How can market mechanism for forest environmental services help the poor? Primary lessons from Latin America. World Developement, 33 (9): 1511-1527.

KARSENTY A., SEMBRÉS T., PERROT-MAîTRE D., 2009. Paiements pour services environnementaux et pays du Sud : La conservation de la nature rattrapée par le développement ? Troisièmes journées de recherches en sciences sociales, Inra/SFRE/Cirad, 9-11 septembre 2009, Montpellier, France.

LANDELL-MILLS N., PORRAS I., 2002. Silver Bullets or Fool's Gold ? A Global Review of Markets for Forest Environmental Services and their Impacts on the Poor. Londres, RoyaumeUni, IIED. http://pubs.iied.org/9066IIED.html

LAURANS Y., LEMÉNAGER T., AOUBID S., 2011. Les paiements pour services environnementaux, de la théorie à la mise en œuvre, quelles perspectives pour les pays en développement? Paris, France, AFD, coll. À Savoir (07), 218 p.

LAVIGNE DELVILLE P., 1997. Le foncier et la gestion des ressources naturelles. In : Cirad, Gret (éds). Le mémento de l'agronome. Paris, France, Cirad, Gret, MAE, 201-221.

MAEP, 2006 Analyse de la filière vanille de 2000 à 2006, Antananarivo, Madagascar, ministère de l'Agriculture, de l'Élevage et de la Pêche, 65 p.

MAYRAND K., PAQUIN M., 2004. Le paiement pour les services environnementaux : Étude et évaluation des systèmes actuels. Montréal, Canada, Unisféra International Centre, 59 p.

MEF, 2014. Fonds de partenariat pour le carbone forestier (FCPF). Proposition des mesures pour l'état de préparation (R-PP). Antananarivo, Madagascar, ministère de l'Environnement et des Forêts, $176 \mathrm{p}$.

RAMAMONJISOA B., 2009. Analyse de l'évolution des stratégies de conservation de la biodiversité à Madagascar. Antananarivo, Madagascar, ministère de l'Environnement, des Eaux et Forêts (Minenvef), $37 \mathrm{p}$.

RANDRIANARISON M., KARPE P., 2010. Efficacité et équité des contrats de conservation à Madagascar. Cas de Didy. Mondes en Développement, 38 (3) : 83-97.

RASOLOARISON O., RAKOTOVAO J. M., BOCKEL L., 2001. Accès au capital, crédit, accès au foncier et pauvreté rurale à Madagascar. Antananarivo, Madagascar, Note d'analyse de l'UPDR, 9 août, 12 p.

RAZAFIARIJAONA J., 2005. Problématiques foncières et développement rural à Madagascar : Dimensions anthropo-juridiques des rapports foncier-environnement. $12 \mathrm{p}$.

TOILLIER A., 2011. Quel schéma de gouvernance pour un mécanisme de Paiement pour services hydrologiques? Le cas de la microcentrale de Tolongoina, Madagascar. Programme Serena, Document de travail n²011-02, 20 p.

WUNDER S., 2005. Payments for environmental services: some nuts and bolts. Bogor, Indonésie, Cifor, Occasional Paper $n^{\circ} 2,32 \mathrm{p}$. 